Published in final edited form as:

Org Lett. 2019 June 07; 21(11): 4355-4358. doi:10.1021/acs.orglett.9b01556.

\title{
Kinetic Resolution of Cyclic Secondary Azides, Using an Enantioselective Copper-Catalyzed Azide-Alkyne Cycloaddition
}

\author{
Juliana R. Alexander ${ }^{\dagger}$, Amy A. Ott ${ }^{\dagger}$, En-Chih Liu, and Joseph J. Topczewski ${ }^{\star}$ \\ Department of Chemistry, University of Minnesota Twin Cities, Minneapolis, Minnesota 55455, \\ United States
}

\begin{abstract}
An enantioselective copper-catalyzed azide- alkyne cycloaddition (E-CuAAC) is reported by kinetic resolution. Chiral triazoles were isolated in high yield with limiting alkyne (up to 97:3 enantiomeric ratio (er)). A range of substrates were tolerated ( $>30$ examples), and the reaction was scaled to $>1 \mathrm{~g}$. The er of a triazole product could be enhanced by recrystallization and the recovered scalemic azide could be racemized and recycled. Recycling the azide allows efficient use of the undesired azide enantiomer.
\end{abstract}

\section{Graphical abstract}<smiles>[R]c1ccccc1[X]C(C)N</smiles>

$(S, S)$-Ar-PYBOX, [Cu],
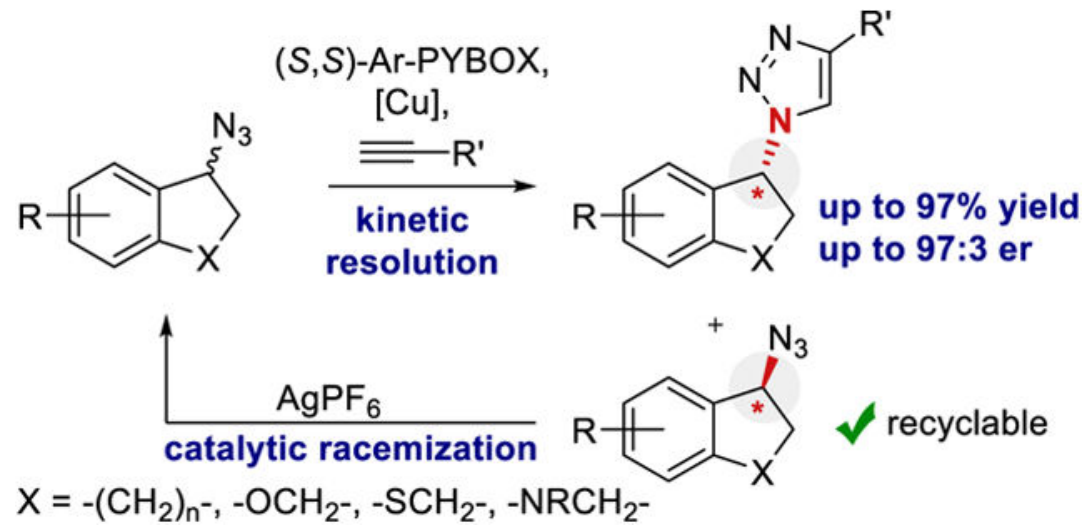

The copper(I) catalyzed azide-alkyne cycloaddition reaction (CuAAC) $)^{1,2}$ is an important transformation. Applications for CuAAC penetrate numerous subdisciplines, including chemical biology, medicinal chemistry, and polymer chemistry. ${ }^{3-5}$ This click reaction ${ }^{6}$ is operationally simple, functional-group-tolerant, high yielding, and broad in scope. Furthermore, the triazole ring is gaining recognition as a protease-resistant peptidomimetic. ${ }^{4}$

*Corresponding Author: jtopczew@umn.edu.

Author Contributions

The manuscript was written through contributions of all authors. All authors have given approval to the final version of the manuscript.

$\dagger$ These authors contributed equally.

Supporting Information

The Supporting Information is available free of charge on the ACS Publications website at DOI: 10.1021/acs.orglett.9b01556.

Procedures, characterization, and spectral and chromatographic data (PDF)

The authors declare no competing financial interest. 
Biologically active $a$-chiral triazoles have been reported (Figure 1) ${ }^{7-12}$ Because of the prevalence of $\boldsymbol{a}$-amino acid-derived amides, an enantioselective CuAAC (E-CuAAC) reaction would be useful for accessing $a$-N-chiral triazoles. However, E-CuAAC has proven challenging in part because (i) both cycloaddition components have linear geometries, (ii) $\mathrm{CuAAC}$ does not require a ligand, and (iii) the product triazole is a competent $\mathrm{CuAAC}$ ligand. ${ }^{13}$ Therefore, ECuAAC must kinetically outcompete the background CuAAC reaction.

A few reports describe kinetic resolution, ${ }^{14-16}$ dynamic kinetic resolution, ${ }^{17}$ or desymmetrization ${ }^{18-21}$ for E-CuAAC. ${ }^{22}$ The majority of successful E-CuAAC reactions generate $a$-C-chiral triazoles, where the new stereocenter is alkyne-derived. ${ }^{15,16,18,20,21}$ The original E-CuAAC reported by Fokin and Finn is the state-of-the-art E-CuAAC kinetic resolution for $a$ - $N$-chiral triazole formation, where the new stereocenter is derived from the azide component (Scheme 1a). ${ }^{14}$ The authors provided only two examples of kinetic resolution with a selectivity factor (s) of 3.2 and 8, respectively (ca. 70:30 er and 84:16 er, assuming $40 \%$ conversion of the azide). Using the same conditions, the desymmetrization of two bis-azides were reported to result predominantly in the formation of bistriazole (not shown).

Our laboratory became interested in using the unique properties of allylic azides to establish $a-N$-chiral centers though dynamic kinetic resolution. ${ }^{23-25}$ Recently, we reported the first ECuAAC reaction that proceeded by dynamic kinetic resolution. ${ }^{17}$ This work prompted an exploration of E-CuAAC by azide kinetic resolution for $a-N$-chiral triazole synthesis (Scheme 1b). Reported herein is a successful expansion of the kinetic resolution by ECuAAC.

Our investigation began with azide 1a, alkyne 2a, and commercially available PYBOX ligands (Table 1, entries 1-3). Minimal enantioselectivity was observed with these ligands, confirming the report from Fokin and Finn. ${ }^{14} \mathrm{~A}$ wide variety of chiral ligands were screened consisting of numerous ligand classes (see Table 1, entries 4 and 5, as well as the Supporting Information). Only the aryl-PYBOX ligands provided reasonable enantioselectivity, with ligand $\mathbf{L 5}$ providing the best selectivity among the ligands screened. The data obtained are reported here with er instead of the selectivity parameter $s$ because (i) er is more synthetically meaningful, (ii) er is directly obtained by chiral HPLC, and (iii) several kinetic assumptions are made when deriving $s$, which are likely faulty for E-CuAAC, based on reported CuAAC kinetics. ${ }^{26,27}$ One could convert the reported er to a presumed $s$ by assuming $40 \%$ conversion for reactions approaching completion. Lowering the reaction temperature resulted in an increase in enantioselectivity, albeit at the cost of conversion (Table 1, entries 6-8). The reaction was faster in $\mathrm{DME}$ or $\mathrm{PhCF}_{3}$ as the solvent, relative to $\mathrm{CH}_{2} \mathrm{Cl}_{2}$, and the enantioselectivity was maintained. When using $\mathrm{PhCF}_{3}$ as the solvent, the reaction was complete within $48 \mathrm{~h}$ (entry 11; see the Supporting Information for additional optimization).

With the optimized conditions in hand, the scope of the alkyne coupling partner was investigated (Scheme 2). The model substrate was isolated in comparable yield and er as expected (3a). Other aryl alkynes were tolerated with electron-rich (3b and $\mathbf{3 c}$ ), electron- 
neutral (3d and 3e), and electron-deficient substituents ( $\mathbf{3 f}-\mathbf{3 h})$ on the arene. Substituents positioned meta and ortho on the aryl alkyne provided good enantioselectivity (3i-3l). Ethyl propiolate (3m), cycloalkyl alkynes (3n and 3o), and a heterocyclic alkyne (entry $\mathbf{3 p}$ ) were tolerated, although several substrates required higher catalyst loadings or longer reaction times to reach higher conversion. Note that long reaction times are not uncommon for other ECuAAC reactions. ${ }^{15,18,19}$

The scope of the azide component that could be kinetically resolved was explored (Scheme 3). Substituents on the chromane arene core were tolerated, including methyl (5a) and halogens (5b-5d). Groups could also be added $a$ to the oxygen atom (5e). Azidotetrahydroquinolines with various $N$-protecting groups $(\mathbf{5 f}-\mathbf{5 h})$ and the free $\mathrm{NH}(\mathbf{5 i})$ provided triazoles in high yield and acceptable enantioselectivity. Azidothiochromanes (5j and $\mathbf{5 k}$ ), azido-dihydrobenzofuran (5l), and azido-indane (5m and $\mathbf{5 n}$ ) could also be resolved. Substrates $\mathbf{5 m}$ and $\mathbf{5 n}$ are noteworthy because the original E-CuAAC reported by Fokin and Finn described this as a problematic substrate $(s<1.3) .{ }^{14}$ Acyclic substrate 50 provided slower conversion and slightly reduced selectivity.

Chiral alkyne 6 was used to test for matched/mismatched behavior (Scheme 4). Treating azide rac-1a with chiral alkyne $\mathbf{6}$ and either enantiomer of ligand $\mathbf{L} \mathbf{4}$ resulted in moderate yield with opposite diastereoselectivity (14:1 and 1:13). This reversal of diastereoselectivity indicates this reaction is under catalyst control.

The kinetic resolution could be successfully scaled to provide more than $1 \mathrm{~g}$ of triazole product (Scheme 5). The initial enantioselectivity was 89:11 er, which corresponds to an $s=$ 13.5. The enantiopurity could be enhanced upon recrystallization (99:1 er). The excess azide was recovered (76:24 er) and racemized upon exposure to catalytic $\mathrm{AgPF}_{6}{ }^{28}$ The azide could then be recycled and used in a subsequent reaction. The ability to recycle the recovered azide improves the overall efficiency of the reaction. The $(R)$-1a enantiomer preferentially reacted with the catalyst derived from ligand (S,S)-L5. This was determined by analyzing scalemic azide recovered from the reaction. The scalemic azide was compared to a sample of $(S)$-1a which was accessed via diazo transfer from commercially available (S)-3,4-dihydro-2H-chromen-4-amine. The same analysis was conducted with azide recovered in the synthesis of triazoles $\mathbf{3 j}$ and $\mathbf{3 p}$, which confirmed the absolute configuration of the product. The configuration of the other triazole products were assigned based on analogy.

This report describes an expanded scope for both the azide and alkyne coupling partners in an E-CuAAC. The products of this kinetic resolution are $a$ - $N$-chiral triazoles and can be obtained in up to $97 \%$ yield and up to $97: 3 \mathrm{er}$. The reaction can be conducted to isolate more than $1 \mathrm{~g}$ of product and the excess azide can be recovered, racemized, and recycled. The er of the product triazoles can be readily improved to 99:1 with a single recrystallization.

\section{Supplementary Material}

Refer to Web version on PubMed Central for supplementary material. 


\section{ACKNOWLEDGMENTS}

This research was supported by the National Institute of General Medical Sciences of the National Institutes of Health, under Award No. R35GM124718. We also acknowledge NIH Shared Instrumentation Grant No. S10OD011952.

\section{REFERENCES}

(1). Tornøe CW; Christensen C; Meldal M Peptidotriazoles on Solid Phase : [1,2,3]-Triazoles by Regiospecific Copper (I)-Catalyzed 1,3-Dipolar Cycloadditions of Terminal Alkynes to Azides. J. Org. Chem 2002, 67, 3057-3064. [PubMed: 11975567]

(2). Rostovtsev VV; Green LG; Fokin VV; Sharpless KB A Stepwise Huisgen Cycloaddition Process: Copper(I)-Catalyzed Regioselective "Ligation" of Azides and Terminal Alkynes. Angew. Chem., Int. Ed 2002, 41, 2596-2599.

(3). Meldal M; Tornøe CW Cu-Catalyzed Azide - Alkyne Cycloaddition. Chem. Rev 2008, 108, 29523015. [PubMed: 18698735]

(4). Pedersen DS; Abell A 1,2,3-Triazoles in Peptidomimetic Chemistry. Eur. J. Org. Chem 2011, 2011, 2399-2411.

(5). Finn MG; Fokin VV Click Chemistry: Function Follows Form. Chem. Soc. Rev 2010, 39, $1231-$ 1232. [PubMed: 20309482]

(6). Kolb HC; Finn MG; Sharpless KB Click Chemistry: Diverse Chemical Function from a Few Good Reactions. Angew. Chem., Int. Ed 2001, 40, 2004-2021.

(7). Ellman JA; Jain RK; Wood WJL; Tsuruoka H; Patterson AW Substrate Activity Screening: A Fragment-Based Method for the Rapid Identification of Nonpeptidic Protease Inhibitors. J. Am. Chem. Soc 2005, 127, 15521-15527. [PubMed: 16262416]

(8). Lee T; Cho M; Ko S-Y; Youn H-J; Baek DJ; Cho W-J; Kang C-Y; Kim S Synthesis and Evaluation of 1,2,3-Triazole Containing Analogues of the Immunostimulane Alpha-GalCer. J. Med. Chem 2007, 50, 585-589. [PubMed: 17266209]

(9). Patterson AW; Wood WJL; Hornsby M; Lesley S; Spraggon G; Ellman JA Identification of Selective, Nonpeptidic Nitrile Inhibitors of Cathepsin S Using the Substrate Activity Screening Method. J. Med. Chem 2006, 49, 6298-6307. [PubMed: 17034136]

(10). Huber K; Hamad B; Kirkpatrick P Fresh from the Pipeline: Ticagrelor. Nat. Rev. Drug Discovery 2011, 10, 255-256. [PubMed: 21455230]

(11). Deprez-Poulain R; Hennuyer N; Bosc D; Liang WG; Enee E; Marechal X; Charton J; Totobenazara J; Berte G; Jahklal J; Verdelet T; et al. Catalytic Site Inhibition of InsulinDegrading Enzyme by a Small Molecule Induces Glucose Intolerance in Mice. Nat. Commun 2015, 6, 1-13.

(12). Mocharla VP; Walsh JC; Padgett HC; Su H; Fueger B; Weber WA; Czernin J; Kolb HC From In Situ to In Vivo: An In Situ Click-Chemistry-Derived Carbonic Anhydrase II Imaging Agent for Positron Emission Tomography. ChemMedChem 2013, 8, 43-48. [PubMed: 23208787]

(13). Rodionov VO; Fokin VV; Finn MG Mechanism of the Ligand-Free CuI-Catalyzed Azide-Alkyne Cycloaddition Reaction. Angew. Chem., Int. Ed 2005, 44, 2210-2215.

(14). Meng JC; Fokin VV; Finn MG Kinetic Resolution by Copper-Catalyzed Azide-Alkyne Cycloaddition. Tetrahedron Lett 2005, 46, 4543-4546.

(15). Brittain WDG; Buckley BR; Fossey JS Kinetic Resolution of Alkyne-Substituted Quaternary Oxindoles via Copper Catalysed Azide-Alkyne Cycloadditions. Chem. Commun 2015, 51, 17217-17220.

(16). Brittain WDG; Chapin BM; Zhai W; Lynch VM; Buckley BR; Anslyn EV; Fossey JS The BullJames Assembly as a Chiral Auxiliary and Shift Reagent in Kinetic Resolution of Alkyne Amines by the CuAAC Reaction. Org. Biomol. Chem 2016, 14, 10778-10782. [PubMed: 27604036]

(17). Liu E-C; Topczewski JJ Enantioselective Copper Catalyzed Alkyne-Azide Cycloaddition by Dynamic Kinetic Resolution. J. Am. Chem. Soc 2019, 141, 5135-5138. [PubMed: 30888164] 
(18). Zhou F; Tan C; Tang J; Zhang YY; Gao WM; Wu HH; Yu YH; Zhou J Asymmetric Copper(I)Catalyzed Azide-Alkyne Cycloaddition to Quaternary Oxindoles. J. Am. Chem. Soc 2013, 135, 10994-10997. [PubMed: 23855917]

(19). Page P; Martin J; Stephenson G; Gaumont A-C; Deschamps D; Buttress J; Lancelot M; Sheldon A; Alayrac C An Investigation of the Asymmetric Huisgen 'Click' Reaction. Synlett 2013, 24, 2723-2729.

(20). Zheng Z-J; Song T; Xu L-W; Deng Y; Xu Z; Zhou W; Li L Enantioselective Copper-Catalyzed Azide-Alkyne Click Cyclo-addition to Desymmetrization of Maleimide-Based Bis(Alkynes). Chem. - Eur. J 2015, 21, 554-558. [PubMed: 25388524]

(21). Osako T; Uozumi Y Enantioposition-Selective Copper-Catalyzed Azide-Alkyne Cycloaddition for Construction of Chiral Biaryl Derivatives. Org. Lett 2014, 16, 5866-5869. [PubMed: 25360824]

(22). Brittain WDG; Buckley BR; Fossey JS Asymmetric Copper-Catalyzed Azide-Alkyne Cycloadditions. ACS Catal 2016, 6, 3629-3636.

(23). Ott AA; Goshey CS; Topczewski JJ Dynamic Kinetic Resolution of Allylic Azides via Asymmetric Dihydroxylation. J. Am. Chem. Soc 2017, 139, 7737-7740. [PubMed: 28574252]

(24). Porter MR; Shaker RM; Calcanas C; Topczewski JJ Stereoselective Dynamic Cyclization of Allylic Azides : Synthesis of Tetralins, Chromanes, and Tetrahydroquinolines. J. Am. Chem. Soc 2018, 140, 1211-1214. [PubMed: 29303567]

(25). Ott AA; Packard MH; Ortuño MA; Johnson A; Suding VP; Cramer CJ; Topczewski JJ Evidence for a Sigmatropic and an Ionic Pathway in the Winstein Rearrangement. J. Org. Chem 2018, 83, 8214-8224. [PubMed: 29870252]

(26). Keith JM; Larrow JF; Jacobsen EN Practical Considerations in Kinetic Resolution Reactions. Adv. Synth. Catal 2001, 343, 5-26.

(27). Worrell BT; Malik JA; Fokin VV Direct Evidence of a Dinuclear Copper Intermediate in Cu(I)Catalyzed Azide-Alkyne Cycloadditions. Science 2013, 340, 457-461. [PubMed: 23558174]

(28). Ott AA; Topczewski JJ Catalytic Racemization of Activated Organic Azides. Org. Lett 2018, 20 , 7253-7256. [PubMed: 30394752] 


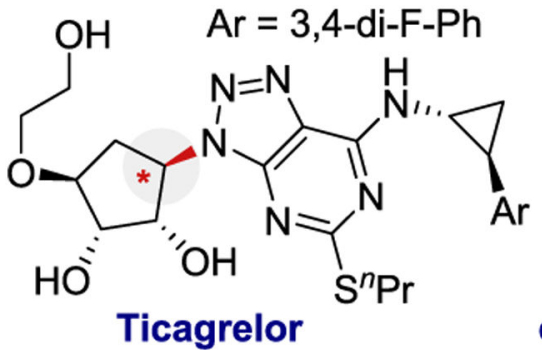

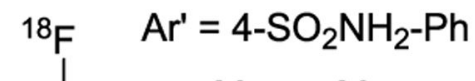<smiles>Cc1ccnc(CI)c1</smiles><smiles>C=C(N)[C@H](C(C)C)N(C)N=N</smiles>
carbonic anhydrase II Ar'

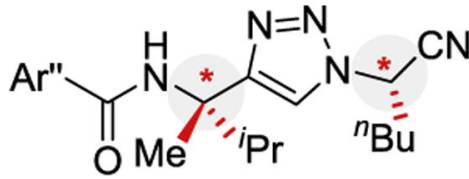
antiaggregant imaging agent for PET

Ar" = 3-thiopheneyl

cathepsin S inhibitor<smiles>[Z20]C[C@H](CC(=O)NO)n1cc(CNC(=O)[Al])nn1</smiles>

insulin-degradation inhibitor

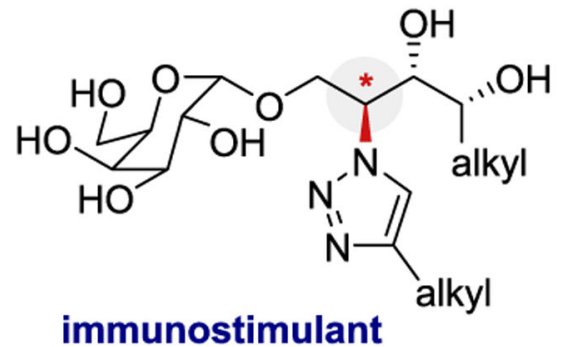

Figure 1.

Representative bioactive $a-N$-chiral triazoles. 


\section{a) Previous}
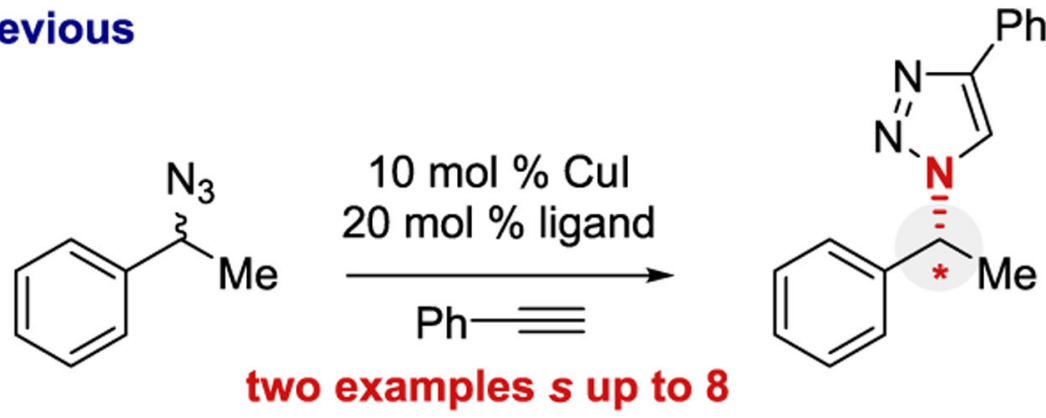

\section{b) This Work}<smiles></smiles>

\section{$2.5 \mathrm{~mol} \%[\mathrm{Cu}]$} $5 \mathrm{~mol} \%$ ligand

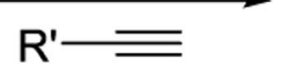<smiles>[R]c1ccc2c(c1)[X]CC2n1cc([R])nn1</smiles>

$$
\mathrm{X}=-\left(\mathrm{CH}_{2}\right)_{\mathrm{n}^{-}},-\mathrm{OCH}_{2^{-}},-\mathrm{SCH}_{2^{-}},-\mathrm{NRCH}_{2}-
$$

Scheme 1.

Azide Kinetic Resolution by E-CuAAC 

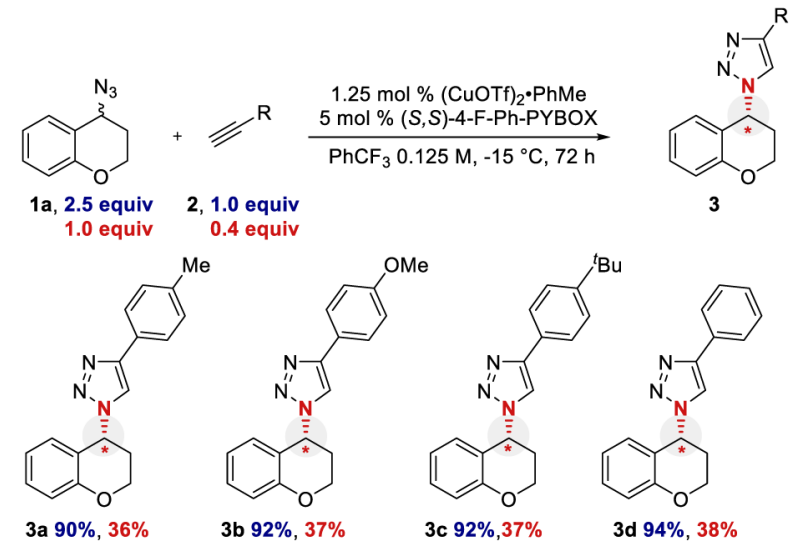

$90: 10$ er

$89: 11$ er

$85: 15$ er

$90: 10$ er

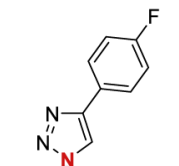

$\mathrm{Cl}$
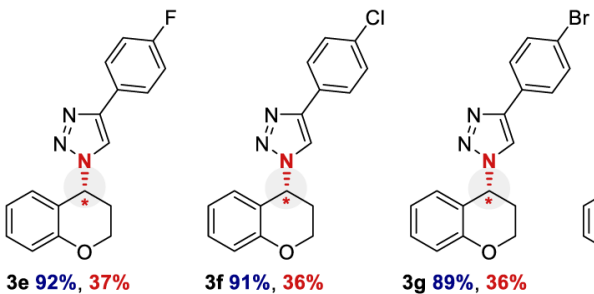

3f $91 \%, 36 \%$

88:12 er

89:11 er
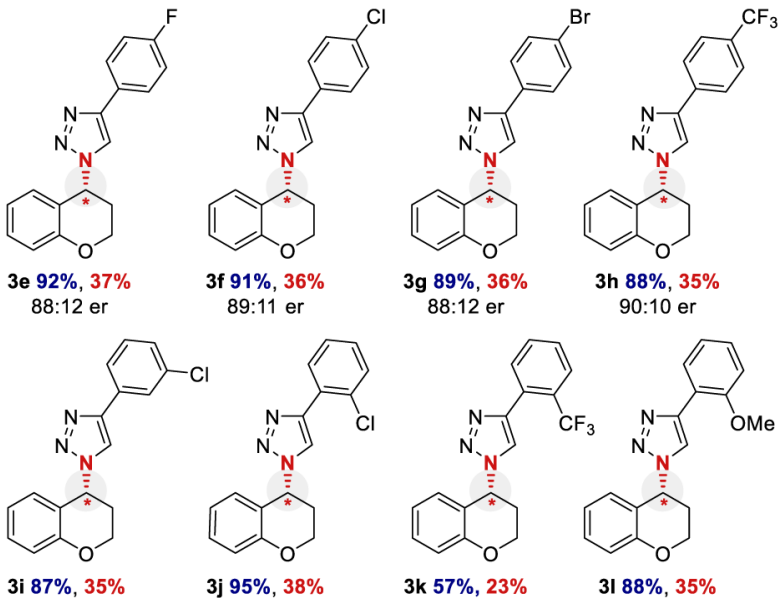

90:10 er

3j $95 \%, 38 \%$

97:3 er

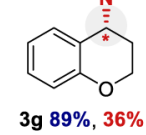

3 g $89 \%, 36 \%$
$88: 12$ er

90:10 er

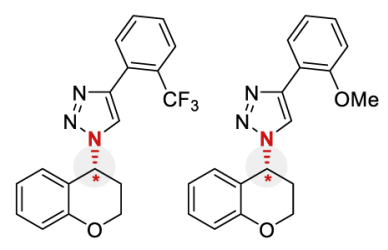

3k $57 \%, 23 \%$

$97: 3 \mathrm{er}^{b}$

3। $\mathbf{8 8} \%, 35 \%$

92:8 er
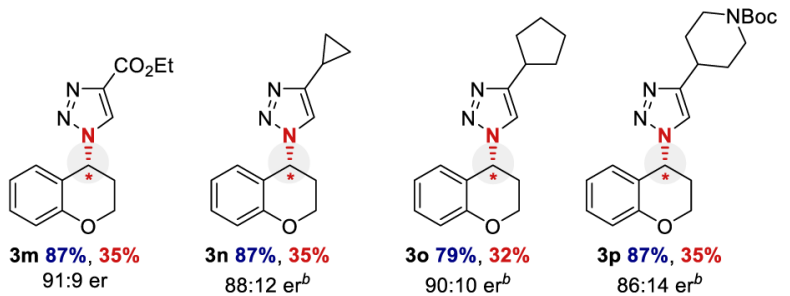

Scheme 2. Substrate Scope of Alkyne Coupling Partner ${ }^{a}$

${ }^{a}$ Isolated yields are reported. The yield is calculated based on either the alkyne (limiting reagent) or azide (kinetic resolution component). Enantiomeric ratio (er) was determined by chiral HPLC. Yield and er values are the average of duplicate trials. ${ }^{b_{2} .5} \mathrm{~mol} \%$ $(\mathrm{CuOTf})_{2} \cdot \mathrm{PhMe}, 10 \mathrm{~mol} \%$ (S,S)-4-F-Ph-PYBOX, and $0.1 \mathrm{M}$ in $\mathrm{PhCF}_{3}$. 

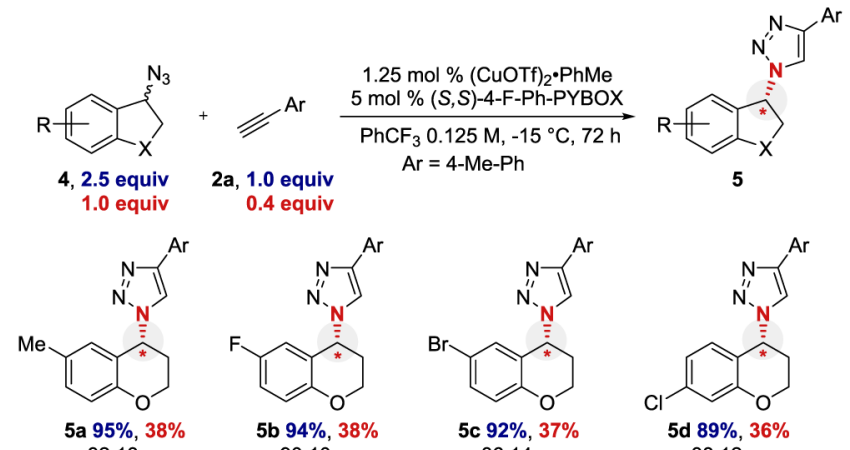

0.4 equiv
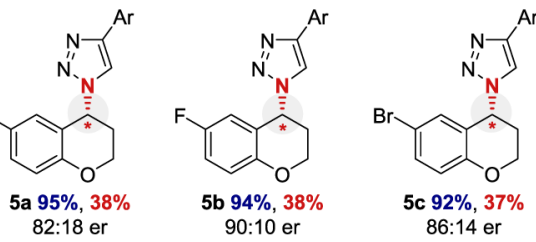

90:10 er

86:14 er
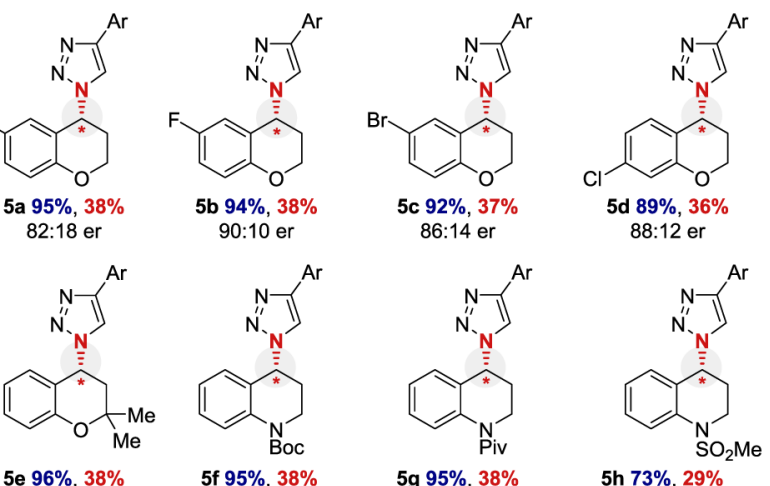

5f $\mathbf{9 5} \%, 38 \%$
$86: 14$ er

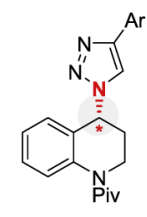

5g $95 \%, 38 \%$
$91: 9$ er

88:12 er

5e $96 \%, 38 \%$
$85: 15$ er
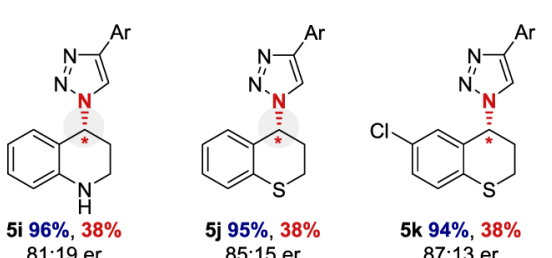

5k 94\%, 38\%

$87: 13$ er

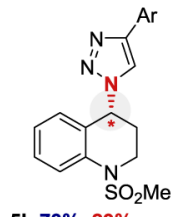

5h $73 \%, 29 \%$

86:14 er

$81: 19$ er

$85: 15$ er

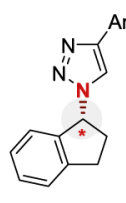

$5 \mathrm{~m} 97 \%, 39 \%$

$94: 6$ er
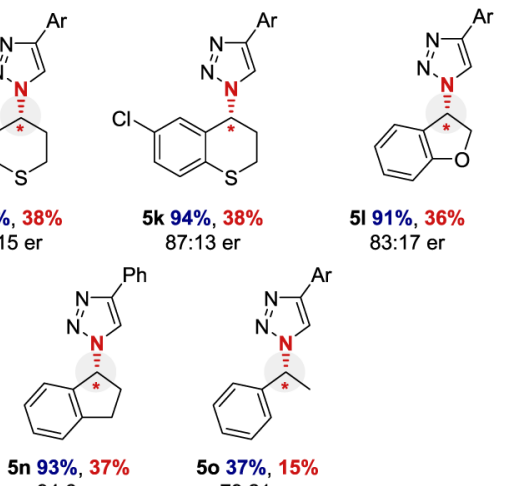

5। $91 \%, 36 \%$

83:17 er

Scheme 3. Substrate Scope of Azide Coupling Partner ${ }^{a}$

${ }^{a}$ Isolated yields are reported. The yield is calculated based on either the alkyne (limiting reagent) or azide (kinetic resolution component). Enantiomeric ratio (er) was determined by chiral HPLC. Yield and er values are the average of duplicate trials. 


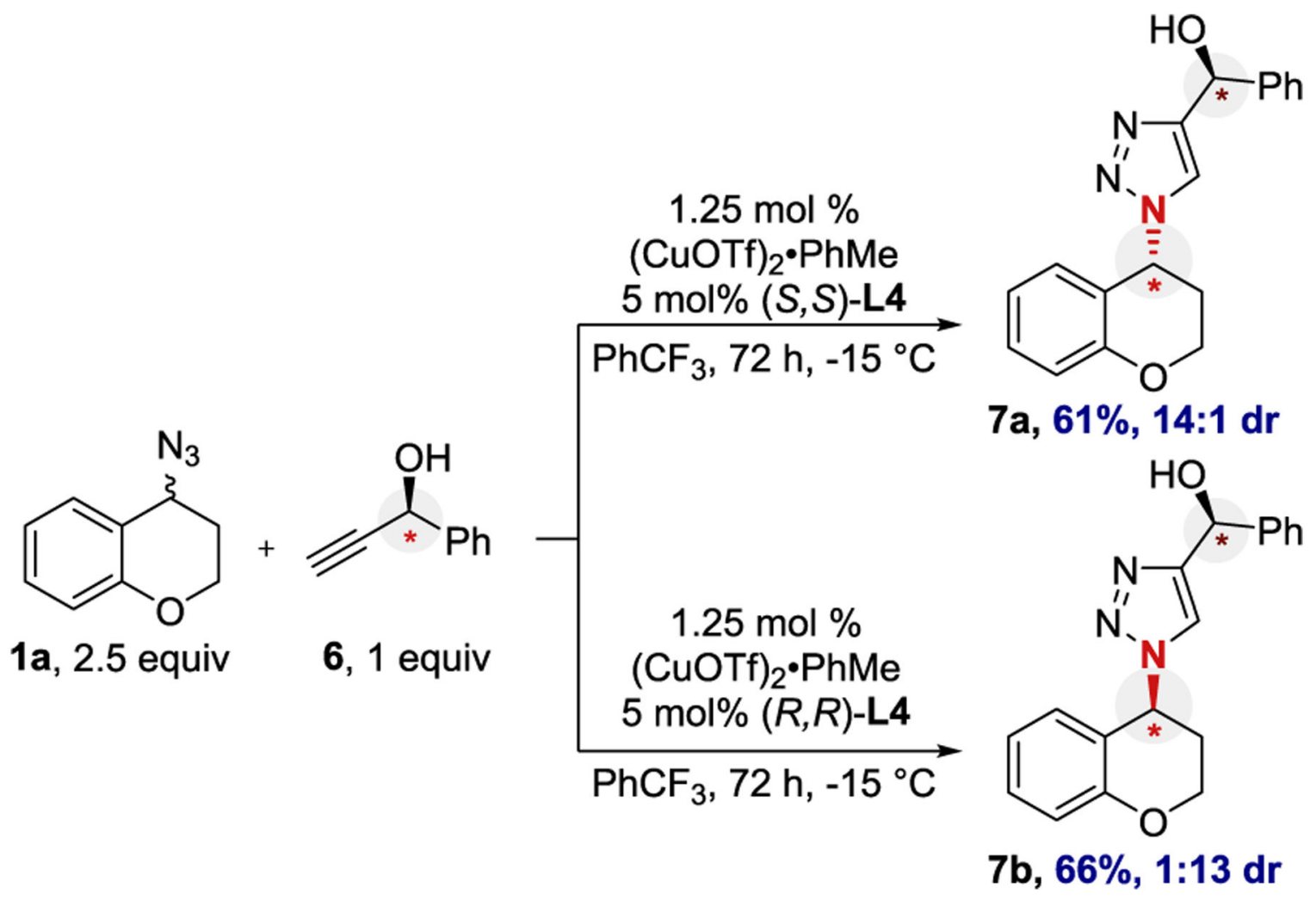

Scheme 4.

Matched/Mismatched Experiment 
<smiles>CCOc1ccccc1C#N</smiles>

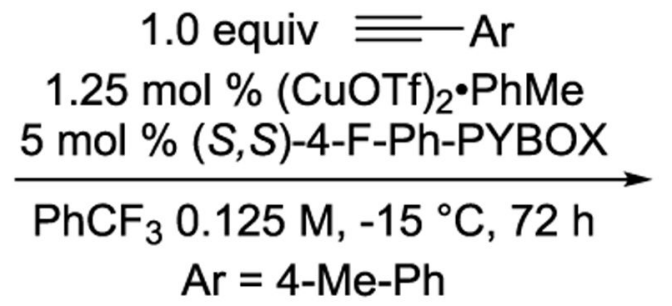

2.5 equiv

rac-1a

$93 \%$ from scalemic 1 a, $83 \%$ from recoverable $1 a$

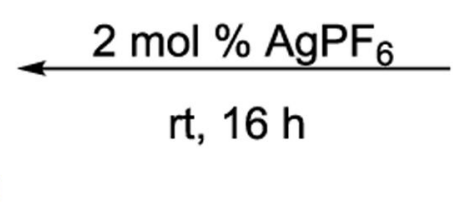

\section{$89 \%$ from recoverable $1 \mathrm{a}$,} 76:24 er

Scheme 5.

Gram-Scale Reaction and Racemization of Recovered Azide 
Table 1.

E-CuAAC Optimization by Kinetic Resolution ${ }^{a}$

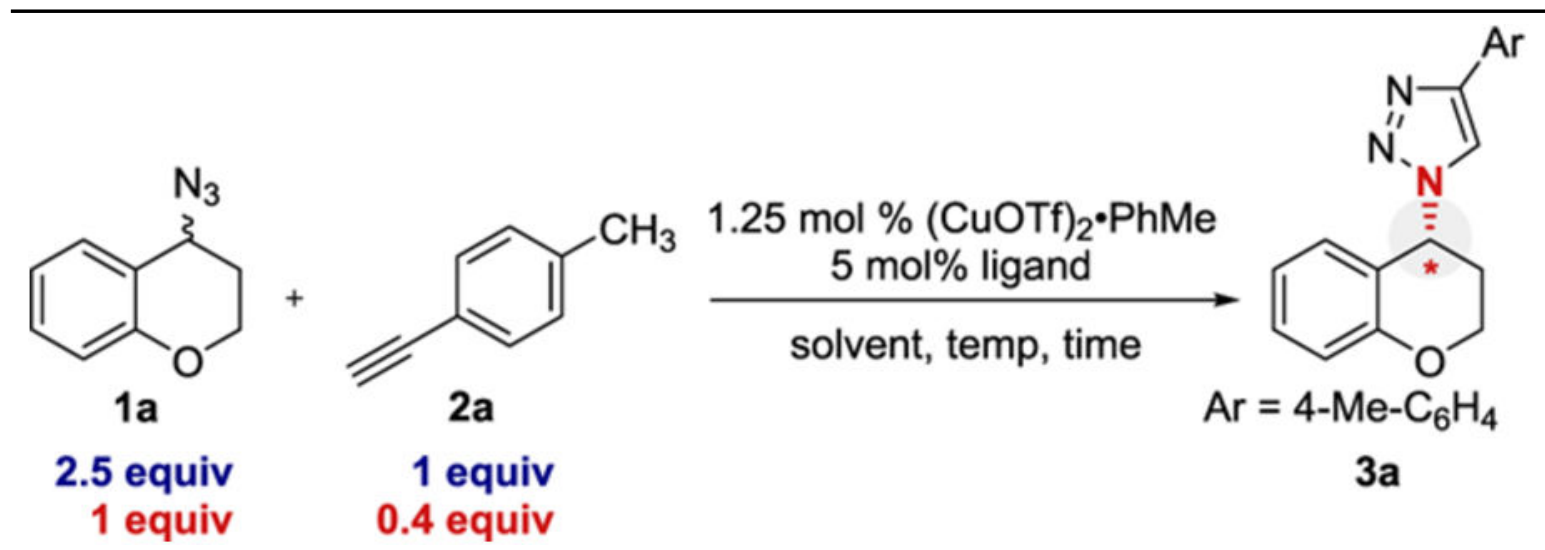

\begin{tabular}{|c|c|c|c|c|c|}
\hline entry & ligand & solvent & Temperature $\left({ }^{\circ} \mathbf{C}\right)$ & yield $^{b}(\%)$ & enantiomeric ratio, er ${ }^{c}$ \\
\hline 1 & $(R)-\mathrm{L} 1$ & $\mathrm{CH}_{2} \mathrm{Cl}_{2}$ & $\mathrm{rt}^{d}$ & $88(35)$ & $55: 45$ \\
\hline 2 & $(R)-\mathrm{L} 2$ & $\mathrm{CH}_{2} \mathrm{Cl}_{2}$ & $\mathrm{rt}^{d}$ & $55(22)$ & $50: 50$ \\
\hline 3 & $(R)-\mathrm{L} 3$ & $\mathrm{CH}_{2} \mathrm{Cl}_{2}$ & $\mathrm{rt}^{d}$ & $92(37)$ & $22: 78$ \\
\hline 4 & $(R)-\mathrm{L} 4$ & $\mathrm{CH}_{2} \mathrm{Cl}_{2}$ & $\mathrm{rt}^{d}$ & $95(38)$ & $21: 79$ \\
\hline 5 & $(S)$-L5 & $\mathrm{CH}_{2} \mathrm{Cl}_{2}$ & $\mathrm{rt}^{d}$ & $96(38)$ & $80: 20$ \\
\hline $6^{e}$ & $(S)$-L5 & $\mathrm{CH}_{2} \mathrm{Cl}_{2}$ & 0 & $84(34)$ & $84: 16$ \\
\hline $7^{e, f}$ & $(S)$-L5 & $\mathrm{CH}_{2} \mathrm{Cl}_{2}$ & -15 & $64(26)$ & $86: 14$ \\
\hline $8^{e, g}$ & $(S)$-L5 & $\mathrm{CH}_{2} \mathrm{Cl}_{2}$ & -20 & $34(14)$ & 89:11 \\
\hline $9^{e, f}$ & $(S)$-L5 & DME & -15 & $87(35)$ & $86: 14$ \\
\hline${ }_{10}{ }^{e, f}$ & $(S)$-L5 & $\mathrm{PhCF}_{3}$ & -15 & $92(37)$ & $88: 12$ \\
\hline${ }_{11}^{e, h}$ & $(S)$-L5 & $\mathrm{PhCF}_{3}$ & -15 & $92(37)$ & $88: 12$ \\
\hline
\end{tabular}

${ }^{a}$ Reactions conducted with azide $\mathbf{1 a}(0.125 \mathrm{mmol})$ and alkyne $\mathbf{2 a}(0.05 \mathrm{mmol})$ at $0.1 \mathrm{M}$ in varying solvent with $(\mathrm{CuOTf}) 2 \cdot \mathrm{PhMe}(0.62 \mu \mathrm{mol})$ and varying ligand $(2.5 \mu \mathrm{mol})$. All yield and er values reflect the average of duplicate trials.

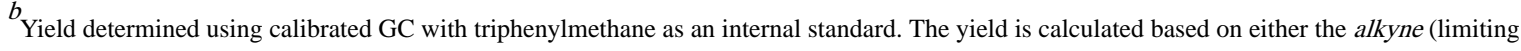
reagent) or azide (kinetic resolution component).

${ }^{c}$ Chiral HPLC was used to determine er.

$d_{\mathrm{rt}=\text { room temperature. }}$

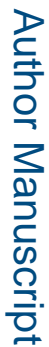

${ }^{e}$ Concentration was $0.125 \mathrm{M}$.

$f_{\text {Time }}=72 \mathrm{~h}$.

$g_{\text {Time }}=96 \mathrm{~h}$

$h_{\text {Time }}=48 \mathrm{~h}$. 


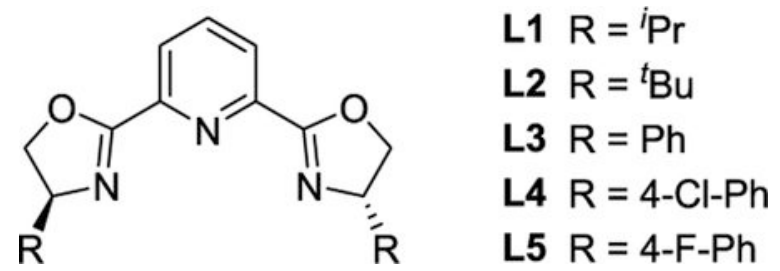

